\title{
Numerical Analysis of the Temperature Field in Luminaires
}

\author{
J. Murín, M. Kropáč, R. Fric
}

This paper contains a calculation of the thermal field caused by electro-heat in lighting devices. After specifying the heat sources, a thermal analysis is make using the finite element method and the equivalent thermal scheme method. The calculated results have been verified experimentally.

Keywords: thermal analysis, luminaire, choke coil, heat loss, surface temperature, finite element method.

\section{Introduction}

Thermal simulations and determination of surface temperatures play a very important role in the design of many engineering applications, including luminaires and their electronic components. Knowing the temperature distribution can help us to achieve optimal properties of the final product. There are two main factors that can be important for thermal analysis of a luminaire:

- Type of light source and control gear; (with the exception of linear and compact fluorescent lamps, all conventional light sources have a declared surface temperature more than $100^{\circ} \mathrm{C}$ ).

- The working conditions of the luminaire; (the external climate or a special kind of surrounding can have an unwelcome influence on the temperature in the luminaire and on the electronic parts inside it).

We assume a luminaire for linear fluorescent lamp IP65, with conventional control gear, which consist of a power-factor capacitor, starting gear and choke coil. This paper contains a numerical analysis of the temperature field in the
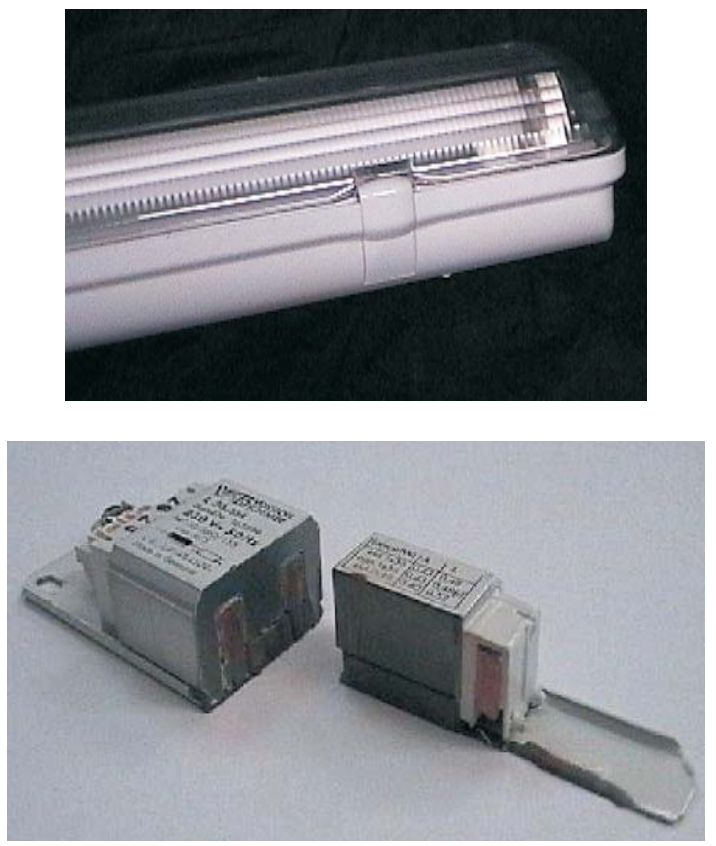

Fig. 1: Example of luminaire for linear fluorescent lamp IP65 and the choke coil choke coil. The heat sources are defined from experimental determination of the heat losses in the choke coil. The results of the numerical analysis are checked by an analytic calculation of the surface temperature using of an equivalent scheme. Finally, an experimental measurement was made of the surface temperature on a real choke coil.

The results and values obtained from the measurements will be used as inputs for a thermal analysis of the whole luminaire.

\section{Experimental determination of the heat loss in the choke coil}

Computing systems based on finite element methods, e.g., ANSYS [1], allow thermal analysis during their design. Using the results of such an analysis the construction and configuration of the components inside the luminaire can be updated in accordance with allowable temperature limits.

In order to describe the heat losses as correctly as possible we need to make the following measurement series:

- resistance measurement on the coil winding;

- measurement on the choke coil;

- measurement on the electric circuit of the light source.

\section{Resistance measurement on the coil winding}

The resistance of the coil winding depends on the operating temperature - the value of the current passing through it. First, we measured the resistance when the temperature of the choke coil was the same as the ambient temperature and then, after the choke coil has been working for 20 minutes when we assume steady running conditions and a constant working temperature.

If the resistance of the coil winding is known and we assume that a nominal current passes through it, we can calculate the Joule heat in the coil winding as

$$
P=R_{N} I_{N}^{2}
$$

$R_{N} \quad$ nominal operating temperature resistance (measured $58.9 \Omega$ ),

$I_{N} \quad$ nominal current,

$P \quad$ Joule heat (calculated $8.06 \mathrm{~W}$ ). 


\section{Measurement on the choke coil}

It is necessary to measure the characteristic curve $P=f(I)$ in the area of current values about the working point of the choke coil, because we are not able to make an accurate $P$ measurement. Then, from $P=f(I)$ we get $P$ of the choke coil for $I_{N}$.

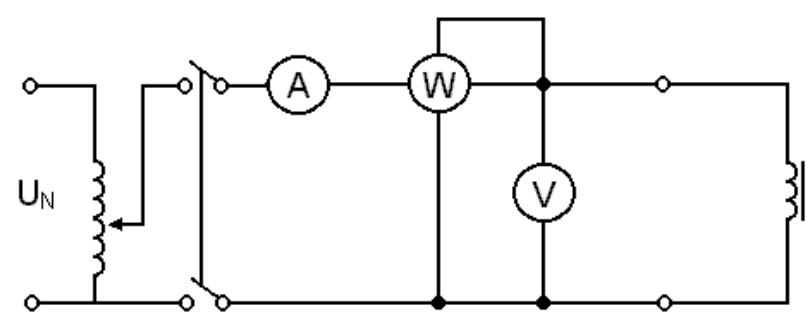

Fig. 2: Measurement on the choke coil

This measurement gives us the total heat loss in the choke coil, and then we obtain the iron heat loss from the following equation:

$$
P_{i}=P-P_{w}
$$

$P_{i} \quad$ iron heat loss,

$P_{w} \quad$ heat loss in coil winding,

$P \quad$ Joule heat.

\section{Measurement on the electric circuit of the light source}

To check the energetic state in the circuit of the light source we have to make the following measurement and find out the general loss of energy in this circuit (Fig. 3).

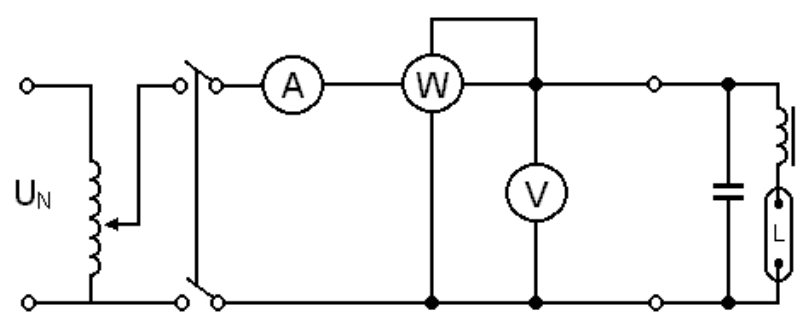

Fig. 3: Measurement on the electric circuit of the light source

We assume that the input power of the light source (fluorescent lamp - 18W) is $17.5-18.5 \mathrm{~W}$, we can ignore the loss in other electric components, so the loss in choke coil is about $12 \mathrm{~W}$, and this value is in accordance with our previous measurement.

This measurement series provides values of the heat sources represented by conventional control gear, which will now be used for the thermal analysis:
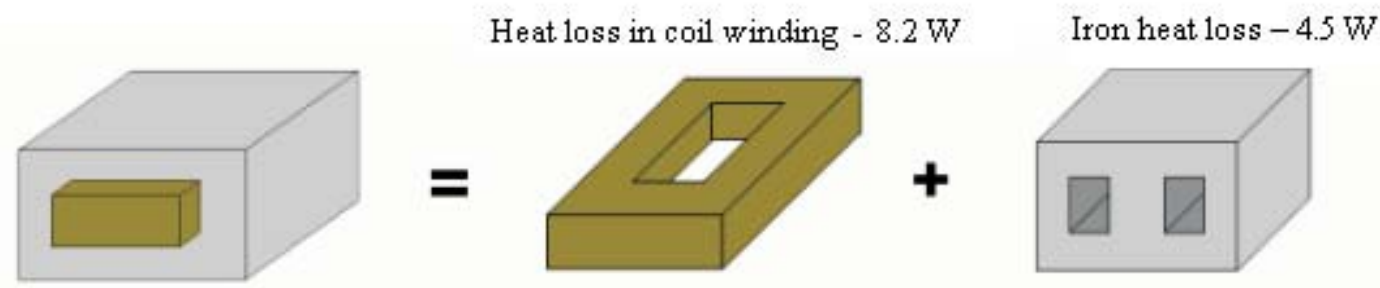

Fig. 4: Heat loss divided in the choke coil

Table 1: Measured and computed parameters

\begin{tabular}{|c|c|c|c|c|c|c|c|c|c|}
\hline \multicolumn{2}{|c|}{ Measured values } & $\begin{array}{c}\text { Current of } \\
\text { choke coil }\end{array}$ & $\begin{array}{c}\text { Loss in meas. } \\
\text { instr. }\end{array}$ & $\begin{array}{c}\text { Heat loss in } \\
\text { choke coil }\end{array}$ & $\begin{array}{c}\text { Heat loss in } \\
\text { coil winding }\end{array}$ & Iron heat loss & \multicolumn{2}{|c|}{$\%$} \\
\hline$U[\mathrm{~V}]$ & $I[\mathrm{~A}]$ & $P^{\prime}[\mathrm{W}]$ & $I_{1}[\mathrm{~A}]$ & $P_{v w}[\mathrm{~W}]$ & $P[\mathrm{~W}]$ & $P_{j}[\mathrm{~W}]$ & $P_{\mathrm{Fe}}[\mathrm{W}]$ & $P_{j}[\mathrm{~W}]$ & $P_{\mathrm{Fe}}[\mathrm{W}]$ \\
\hline 230 & 0.396 & 20 & 0.36 & 8.45 & 11.55 & 7.60 & 3.95 & 66 & 34 \\
\hline 232 & 0.401 & 20.5 & 0.36 & 8.60 & 11.90 & 7.80 & 4.10 & 66 & 34 \\
\hline 234 & 0.402 & 21 & 0.36 & 8.75 & 12.25 & 7.83 & 4.42 & 64 & 36 \\
\hline 236 & 0.407 & 21.5 & 0.37 & 8.90 & 12.60 & 8.03 & 4.57 & 64 & 36 \\
\hline 238 & 0.410 & 22 & 0.37 & 9.05 & 12.95 & 8.15 & 4.80 & 63 & 37 \\
\hline 240 & 0.421 & 22.5 & 0.38 & 9.20 & 13.30 & 8.62 & 4.67 & 65 & 35 \\
\hline
\end{tabular}




\section{Analytic calculation of surface temperature}

For an analytic calculation of the surface temperature we assume:

- choke coil represents the heat source, where heat generation is constant in the whole volume,

- the ambient heat sources are irrelevant,

- the heat from the surface is transferred by convection and radiation (see Fig. 5).

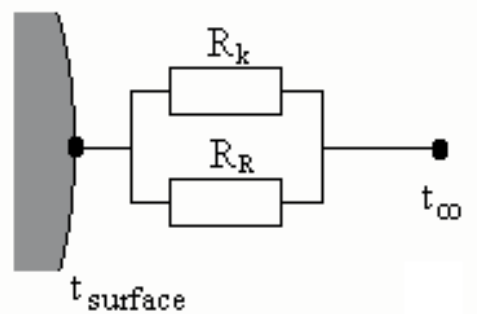

Fig. 5: Equivalent thermal scheme for analytic calculation of the surface temperature

Heat resistances $R_{\mathrm{k}}$ (convection) and $R_{\mathrm{R}}$ (radiation) depend on the surface temperature, so that iterative operation of the final surface temperature must be used, ref. [2], [3].

\section{STEP I. Inputs for calculation}

- Joule heat losses $P[\mathrm{~W}]$

- Surface of choke coil $A\left[\mathrm{~m}^{2}\right]$

- Characteristic dimension $L[\mathrm{~m}]$

- Emissivity of surface $\varepsilon$ [-]

- Ambient temperature $t_{\infty}\left[{ }^{\circ} \mathrm{C}\right]$

STEP II. Calculation of heat resistance

$$
R_{\mathrm{k}}=\frac{L}{N u \lambda A}
$$

$R_{\mathrm{k}} \quad$ convection resistance

$L \quad$ characteristic dimension

$\mathrm{Nu} \quad$ Nusselt s number $\lambda \quad$ air heat conduction coefficient

$A \quad$ surface of choke coil

$$
R_{\mathrm{R}}=\frac{t_{s}-t_{\infty}}{\varepsilon C_{0} A\left[\left(\frac{T_{s}}{100}\right)^{4}-\left(\frac{T_{\infty}}{100}\right)^{4}\right]}
$$

$R_{\mathrm{R}} \quad$ radiation resistance

$\varepsilon \quad$ surface emissivity

$C_{0} \quad$ emissivity of the black body surface

$t_{s} \quad$ surface temperature

$t_{\infty} \quad$ ambient temperature

STEP III. Surface temperature calculation

$$
R=\frac{R_{\mathrm{k}} R_{\mathrm{R}}}{R_{\mathrm{k}}+R_{\mathrm{R}}}
$$

$R \quad$ total heat resistance

$R_{\mathrm{k}} \quad$ convection resistance

$R_{\mathrm{R}} \quad$ radiation resistance

$$
t_{s}=P R+t_{\infty}
$$

$R \quad$ total heat resistance

$P \quad$ heat losses

$t_{s} \quad$ surface temperature

$t_{\infty} \quad$ ambient temperature

The iteration cycle will repeat STEP II. and STEP III., until the surface temperature difference in the cycles is $\Delta t \leq 0.1^{\circ} \mathrm{C}$

\section{Numerical modelling of the heat source in a lighting device}

Following the previous analysis, conditions of unambiguity for evaluation of the temperature rise in the choke coil can be specified by the finite element method (FEM, [4]).

The choke coil was modelled as a box with an assembly plate and with separated volumes of the coil winding and the magnetic circuit iron. We applied the appropriate boundary conditions and material properties to these volumes.

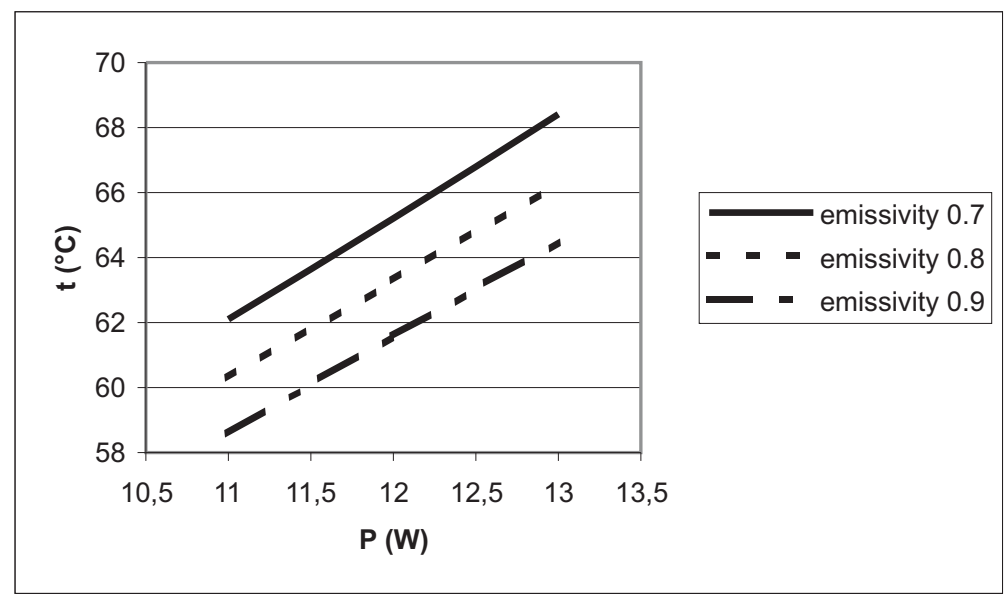

Fig. 6: Analytic calculation of the surface temperature for different emissivity and Joule heat losses 


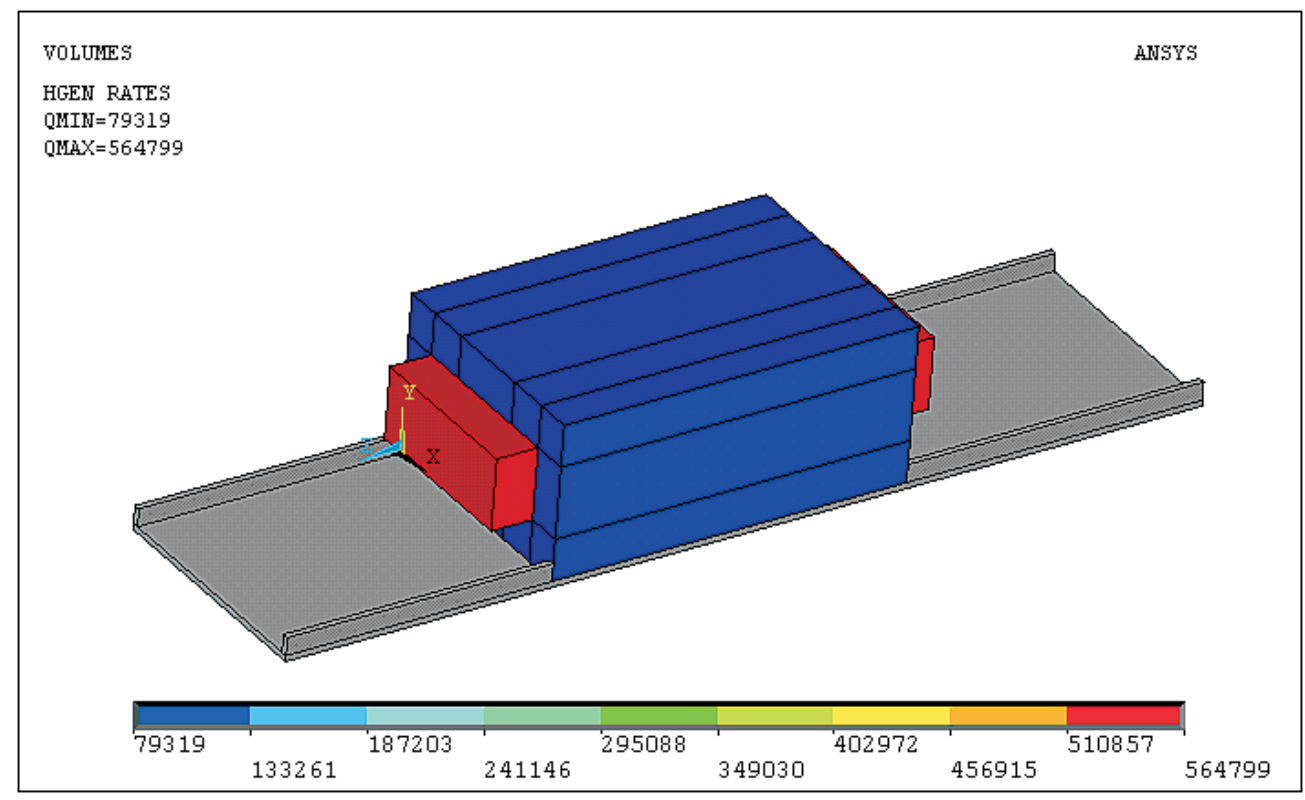

Fig. 7: Volumes and heat generation (W/ $/ \mathrm{m}^{3}$, ANSYS)

Table 2: Heat generation in materials of the choke coil

\begin{tabular}{|c|c|c|c|}
\hline Material & $\begin{array}{c}\text { Generated } \\
\text { heat } \\
{\left[\mathrm{W} / \mathrm{m}^{3}\right]}\end{array}$ & $\begin{array}{c}\text { Generated } \\
\text { heat } \\
{[\mathrm{W}]}\end{array}$ & $\begin{array}{c}\text { Thermal } \\
\text { conductivity } \\
{[\mathrm{W} / \mathrm{m} \mathrm{K}]}\end{array}$ \\
\hline $\mathrm{Cu}$ & 564799 & 8.35 & 380 \\
\hline $\mathrm{Fe}$ & 79319 & 4.15 & 67 \\
\hline
\end{tabular}

We defined the heat flux conditions on the surfaces. The heat was generated in both thecoil winding and the iron (heat loss caused by the eddy current). We assumed that the choke coil was hanging in the air and the heat from the surface was transferred by convection and radiation into space.
Table 3: Expected parameters of convection and radiation of the heat

\begin{tabular}{|c|c|}
\hline Surface emissivity & $0.7-0.9$ \\
\hline Bulk temperature & $19^{\circ} \mathrm{C}$ \\
\hline Coef. of convection & $7.5-9.5$ \\
\hline
\end{tabular}

We evaluated the heat convection coefficient from the criteria equations by the iteration cycle, where the final value is $\alpha=8.5 \mathrm{~W} / \mathrm{m}^{2} \mathrm{~K}$. In real cases the coefficient value can vary betwen 7.5 and 9.5 . Next, we assumed the surface emissivity of the radiation to be in the range $0.7 \sim 0.9$.
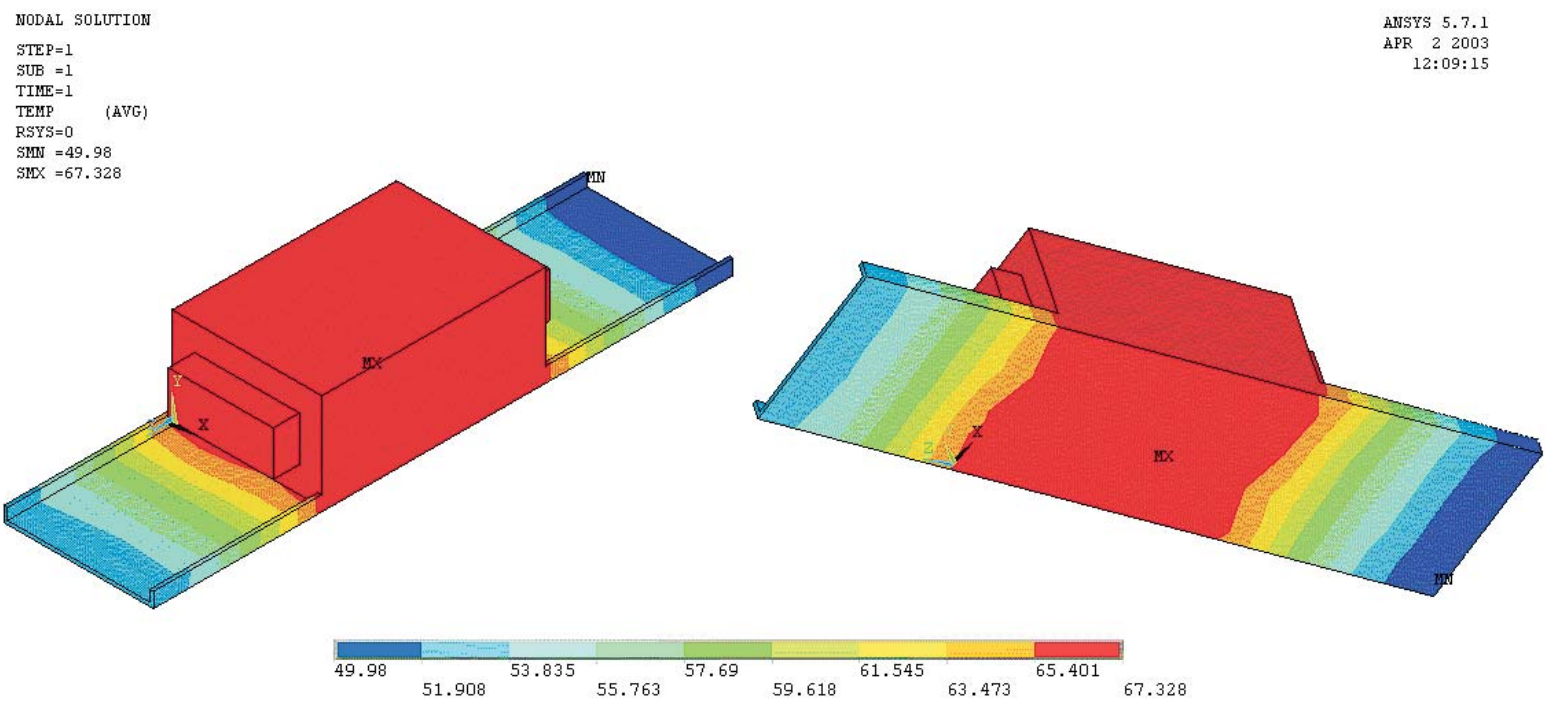

Fig. 8: Temperature field on the surface of the choke coil $\left(\alpha=8.5 \mathrm{~W} / \mathrm{m}^{2} \mathrm{~K} ; \varepsilon=0.8\right)$ 
We assumed two marginal extreme cases, in which we obtain minimum and maximum possible values of the heat and temperatures. The real temperature will occur within this range (between these two values).

Table 4: Temperature of the choke coil in extreme cases

\begin{tabular}{|l|c|c|c|}
\hline Surface emissivity & 0.7 & $\mathbf{0 . 8}$ & 0.9 \\
\hline Coef. of convection & 7.5 & $\mathbf{8 . 5}$ & 9.5 \\
\hline Final maximum temperature $\left[{ }^{\circ} \mathrm{C}\right]$ & $\mathbf{7 2 . 9}$ & $\mathbf{6 7 , 3}$ & $\mathbf{6 2 . 9}$ \\
\hline Final minimum temperature $\left[{ }^{\circ} \mathrm{C}\right]$ & 55.1 & $\mathbf{5 0}$ & 45.9 \\
\hline
\end{tabular}

We modelled the temperature field in the choke coil by the ANSYS program [1], using 3D solid and surface elements.
The boundary conditions applied by the modelling corresponded to the conditions from the measurements of the heating of the real choke coil. The results of the analysis (using average values of the emission and convection coefficients) are displayed in Figs. 8, 9 and 10.

\section{Measurement of the temperature rise in the choke coil}

As a verification of the numerical analysis results, we measured the heating of the real choke coil. The measurement was performed under the same conditions as those assumed in the numerical analysis - with the choke coil hanging in the air. The coil was fed by its nominal current $\boldsymbol{I}_{\boldsymbol{N}}=\mathbf{0 . 3 7} \mathrm{A}$.

Measurement of the surface temperatures was performed by several Cu-Ko heat-sensors installed on the choke coil sur-
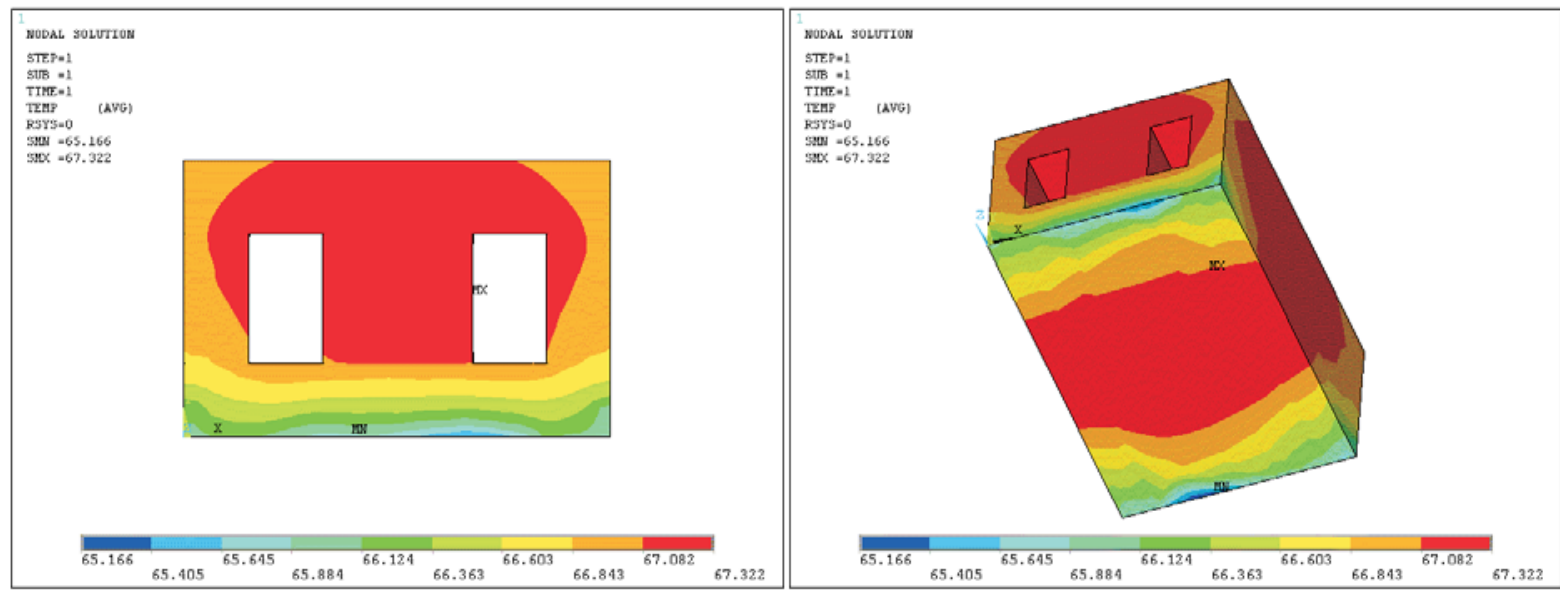

Fig. 9: Temperature field of the iron magnetic circuit $\left(\alpha=8.5 \mathrm{~W} / \mathrm{m}^{2} \mathrm{~K} ; \varepsilon=0.8\right)$

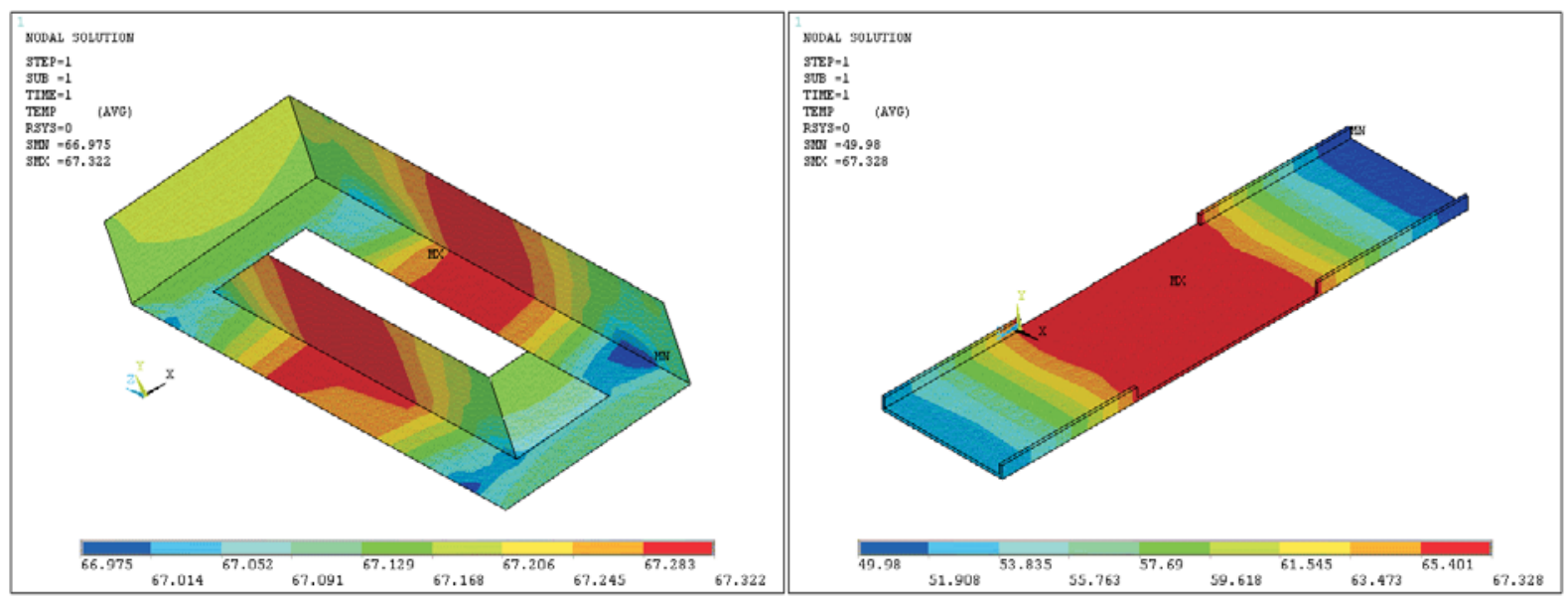

Fig. 10: Temperature field of the copper coil and assembly sheet $\left(\alpha=8.5 \mathrm{~W} / \mathrm{m}^{2} \mathrm{~K} ; \varepsilon=0.8\right)$ 

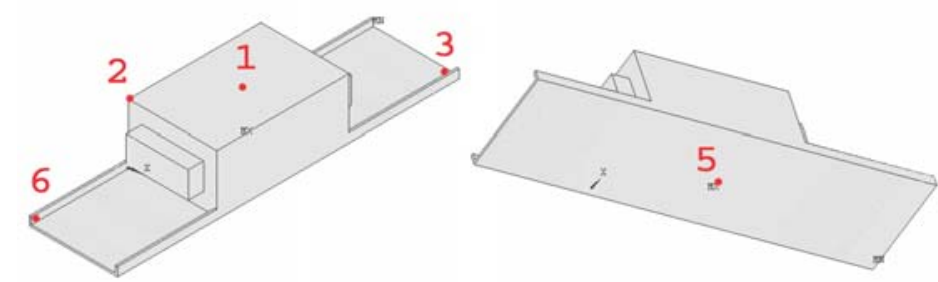

Fig. 11: Temperature measurement points

face at the locations displayed in Fig. 11 (Sensor No. 4 remained free to check the bulk temperature).

The measurement was dynamic and ran during the first two thirds of the heating curve. The final temperature was approximated according to the slope of the heating curve. The increases in the temperature (heating curve) for each measurement point are displayed in Fig. 12.

The following temperature values were measured:

- Maximum measured temperature: $68.5^{\circ} \mathrm{C}$ - at point 5 .

- Minimum measured temperature: $41^{\circ} \mathrm{C}$ - at point 3 .

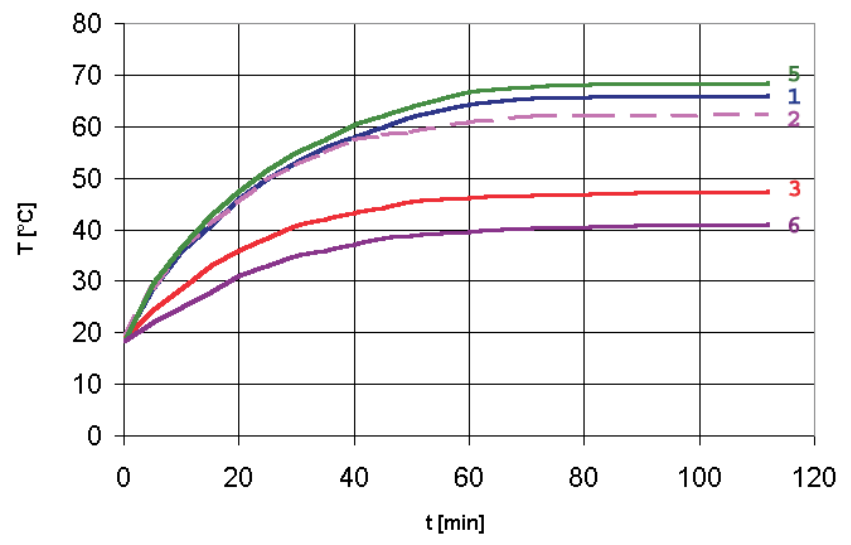

Fig. 12: Temperature rise curves of the choke coil

\section{Conclusion}

It can be seen that our results for numerical and analytical analyses of the surface temperature correspond to the measured values. The differences in the lowest temperatures can be caused by the fact that the real abrasive and multiform surface is too difficult to model, so we cannot create an exact and precise model of the choke coil. Nevertheless, in general we can state that measuring of the surface temperature confirmed the results of one numerical analysis obtained by
ANSYS, as regards both the values and the distribution, so we can use them in a thermal analysis of the whole luminaire.

\section{References}

[1] ANSYS 5.7, Theory manual

[2] Kalousek M., Hučko B.: Prenos tepla. Bratislava: Vydavatelstvo STU, 1996.

[3] Janíček F., Murín J., Lelák J.: "Load Conditions and Evaluation of the Rise of Temperature in an Enclosed Conductor". Journal of Electrical Engineering, Vol. 52, No. 7-8, 2001, p. 210-215.

[4] Rao S. S.: The Finite Element Method in Engineering. Oxford: Pergamon Press, 1982.

Prof. Ing. Justín Murín, DrSc.

phone:+420260291452

fax.:+420 265427192

e-mail: justin.murin@elf.stuba.sk

Department of Mechanics

Ing. Miroslav Kropáč

phone:+420260291 151

fax.:+420265425826

e-mail:kropac@elf.stuba.sk

Department of Power Engineering

Ing. Róbert Fric

phone:+420260291415

fax.:+420 265427192

e-mail: fric@elf.stuba.sk

\section{Department of Mechanics}

Slovak University of Technology in Bratislava

Faculty of Electrical Engineering and

Information Technology

Ilkovičova 3

81219 Bratislava, Slovak Republic 